\title{
Age, the environment and our reproductive future: bonking baby boomers and the future of sex
}

\author{
R John Aitken \\ Discipline of Biological Sciences, Faculty of Science and IT, Hunter Medical Research Institute, Priority Research \\ Centre in Reproductive Science, University of Newcastle, Newcastle, New South Wales 2308, Australia
}

Correspondence should be addressed to R J Aitken; Email: john.aitken@newcastle.edu.au

\begin{abstract}
There has never been a greater need for scientists trained in reproductive science. Most developed countries are witnessing unprecedented rates of recourse to assisted conception sitting cheek-by-jowl with high rates of induced abortion. This article addresses these two incongruous faces of reproductive healthcare. Every year at least 44 million abortions are performed worldwide, many under unsafe and insanitary conditions that carry a significant risk to the lives of women deprived of safe, effective methods for controlling their fertility. Although birth control is a complex issue involving myriad social and political factors, the technical vacuum in this area is significant. Through no fault of the family planning authorities, there have been no radically new methods of fertility control since the oral contraceptive pill was introduced in 1960 and even this contribution to planned parenthood has its roots in the biochemistry of the $\mathbf{1 9 2 0 s}$ and 1930s. Moreover, the pharmaceutical industry has, by and large, turned its back on fundamental research activities in this area. At present, our major investment in reproductive healthcare involves treating ever-increasing numbers of couples with assisted reproductive technologies (ART). However, these treatments are often delivered without critically considering the underlying causes of this condition or seriously contemplating the long-term consequences of the current enthusiasm for such therapy. Significantly, the clinical factors underpinning the commitment of couples to ART include advanced maternal age and a variety of lifestyle factors, such as smoking and obesity, which are known to compromise the developmental potential of the oocyte and DNA integrity in spermatozoa. Reproduction (2014) 147 S1-S11
\end{abstract}

\section{Introduction}

This paper is about the future of sex. As the text is the subject of a public lecture, it will deal with the broad sweep of issues defining our reproductive future rather than a detailed analysis of the reproductive process. We shall examine current trends in human fertility, the impact of genetics and the environment in shaping our capacity to procreate and the need for dramatic improvements in contraceptive practice. It poses questions about the influence of affluence and the environment on reproductive patterns and looks at the fate that awaits any baby boomer still contemplating parenthood.

\section{A reproductive conundrum}

We live in strange times. On the one hand middle class, middle aged couples are taking up assisted conception therapy with increasing alacrity while on the other we are seeing high rates of induced abortion and a virtual cessation of research into new methods of fertility

Sex in three cities: invited lectures series is sponsored by the Society for Reproduction and Fertility. regulation in both public and private sectors. Recent analyses have indicated that the contraceptive needs of some 220 million women in developing countries go unmet every year (Darroch 2013). As a result over a third of the estimated 205 million pregnancies that occur every year are unplanned and unintended and $21 \%$ end in abortion (Sedgh et al. 2012). This equates to an annual abortion figure of around 44 million - and these are just the pregnancy terminations that are registered and available for scrutiny in public sector databases; the real figure will inevitably be much higher. Furthermore, $86 \%$ of these terminations take place in developing countries and almost half (49\%) under unsafe conditions. If safe, effective contraceptive methods were available, over 50 million unwanted pregnancies, at least 22 million abortions, 1.4 million infant deaths and 79000 abortion-related maternal deaths could be avoided each year (Barot 2008, Darroch 2013).

Looking into the future of fertility regulation, there is very little sign that the situation is going to improve. 'Big Pharma' has largely pulled out of this field of endeavour and national medical research agencies such as the NHMRC in Australia and the MRC in the UK have launched no new initiatives in reproductive healthcare. 
Quite the opposite, the MRC has closed its dedicated Reproductive Biology Unit in Edinburgh, which was originally set up in the 1970s under the Directorship of Roger Short with the specific goal of improving our understanding of the molecular mechanisms that drive the reproductive process and to use this information to advance clinical practice in Obstetrics and Gynaecology - including the development of novel approaches to fertility regulation. This research scored some notable wins, such as pioneering the use of RU486 as a post-coital contraceptive (Glasier et al. 1992); however, the original emphasis on contraception gradually dissipated with the passage of time, in keeping with international trends.

The neglect in this area is as curious as it is irrational. In 2008, the International Agency for Research on Cancer estimated that there were 7.7 million deaths from cancer worldwide while in the same year over 44 million pregnancies were terminated by abortion. Whether a previable foetus is comparable to a living human being is a matter of debate and personal conscience. Nevertheless, it is noteworthy that every year we spend billions of dollars supporting large biomedical research institutes in developed countries conducting fundamental research into the diagnosis and treatment of cancer and yet we spend practically nothing on trying to improve a technology that has remained fundamentally unchanged since the introduction of the contraceptive pill in 1960. Over the intervening years, we may have seen some incremental advances in the pharmacology and formulation of contraceptive steroids, but we have seen nothing radically new. There are still no safe, effective contraceptive vaccines, no reversible methods of fertility regulation for men and no dualpurpose contraceptive agents that will provide the user with simultaneous protection against unwanted fertility and infection with a sexually transmitted disease. There are also no forms of contraceptives-on-demand that can be taken around the time of intercourse to prevent conception, despite general recognition that such methods need to be developed (Aitken et al. 2008). Previous attempts to develop contraceptives-on-demand focused on the use of antiprogestins as once-a-month inducers of menstruation more than 20 years ago. However, the commercial development of these reagents was impaired by the reluctance of pharmaceutical companies and funding agencies to invest in a method exhibiting an abortifacient mechanism-of-action (Baird \& Glasier 1999, Baird 2001).

When we consider how recent advances in molecular medicine have transformed healthcare over the past halfcentury, it is remarkable that something that touches all of our lives should be so thoroughly neglected. Admittedly, the specification for new contraceptive agents - that they should at least equal the contraceptive efficacy of the 'pill' and yet be free of adverse side effects - is daunting, given that contraceptives are the only drugs we give to perfectly healthy people. Whereas most pharmaceuticals are taken up following a careful consideration of the balance of benefits and risk, in the case of contraceptives the demand is for modalities that are all benefit and no risk. Nevertheless, the inherent difficulty of the problem should not discourage any attempt to find a resolution. If we had as many scientists and institutions working on contraception as we have on cancer, there would be every chance of securing breakthroughs capable of preventing the unnecessary termination of millions of pregnancies a year.

On the other side of the reproductive coin, there has been an explosion of interest and scientific advance in assisted conception, culminating in the Nobel prize in Physiology or Medicine awarded to Prof. Sir Bob Edwards in 2010. Assisted conception therapy accounts for $1.4 \%$ of all children born in the USA (Sunderam et al. 2012), 3.3\% of children born in Australia (Chambers et al. 2011) and 5.6\% of children in born in Denmark (Hvidtjørn et al. 2011). The reasons behind this increased uptake of assisted conception therapy are complex but appear to be largely a consequence of the high incidence of spontaneous male infertility that plagues our species and the advanced age at which couples are now attempting to start their families. Which brings us to the baby boomers.

\section{Age and reproduction: the female perspective}

Age has a dramatic effect on our capacity to reproduce. In hunter gatherer societies, couples have their first child when they are $<20$ years old and then, in the complete absence of contraception, go on to have around five children. For such women, reproductive life is an alternating succession of pregnancy and lactational amenorrhoea that continues until menopause (Konner \& Worthman 1980). Contrast this ancient, archetypal pattern of reproduction with modern day women in Edinburgh, Nottingham or London. In Western Society, women do not start their families until they enter their 30s. The median age of first fathers in Australia is 33 years while the equivalent age for women is 30.6 years (Australian Bureau of Statistics, 2012). In the USA, the number of first births to women aged 35-39 years increased by 36\% between 1991 and 2001 and the rate among women aged $40-44$ by a staggering $70 \%$ (Heffner 2004). Such is the pressure for modern career-minded women to meet their twin goals of having a family and achieving their professional aspirations that a delay in childbearing is inevitable.

The major problem with this strategy is that female fertility declines precipitously between the ages of 35 and 42 years. The evidence for such a decline is incontrovertible and comes from both historical records and, more recently, from data generated by assisted conception clinics (Human Fertilisation and Embryology Authority 2010). Of course, there is a significant variation within these figures and occasional examples 
of older women miraculously conceiving a child not only exist but also have encouraged some journalists to question the significance of age-dependent declines in female fertility. For example, the front cover of the Observer colour magazine recently trumpeted that 'Everything you know about fertility is wrong' because 'the biological clock does not run as fast as we have been told' (Twenge 2013).

Although it is clearly important to avoid unnecessary panic, the data indicating a precipitous loss of fertility as women progress beyond the age of 35 years are irrefutable. Detailed records of fertility and miscarriage rates, calculated on the basis of ten different populations living between the 17th and the 20th centuries that did not use contraceptives, demonstrate such a decline (Heffner 2004). These data reveal that fertility remains relatively constant up the age of 30 years, giving $>400$ pregnancies/1000 exposed women per year but then begins to decrease substantially. By the age of 45 years, the fertility rate has fallen to around $10 \%$ (100 pregnancies/1000 exposed women; Heffner 2004). Of course, these are population statistics and cannot predict the fate of individuals who may lose their fertility substantially before or after their 40th birthday, depending on a range of other factors. Studies from IVF centres tell us that for women aged 43 and 44 years the overall live birth rate was 8.3 and $5.3 \%$ per initiated cycle respectively, but there were no clinical pregnancies in women $\geq 45$ years old (Cetinkaya et al. 2013).

This midlife decline in human fertility sets our species apart from all other primates, where mortality and reproductive lifespan are coincident and very few individuals experience reproductive senescence before death (Alberts et al. 2013). The reason for this is unknown but may simply be that we have, as a consequence of improvements in primary health care, managed to push the limits of human mortality beyond the lifespan of the primordial follicle population.

Importantly, it is the oocyte population that loses developmental potential rather the reproductive tract's ability to carry a pregnancy. Thus if donor oocytes from younger women are used for IVF-embryo transfer, women are capable of carrying a pregnancy to term in their 60s (Shufaro \& Schenker 2012). The loss of oocyte function with age appears to be largely due to chromosomal nondisjunction leading to the generation of lethal aneuploidies, as ageing eggs attempt to complete meiosis (Fragouli et al. 2013). In addition, age-dependent damage to the oocyte's mitochondria may make the resulting embryos particularly prone to high rates of apoptotic cell death (Check et al. 2013). The significance of these mechanistic studies is that they confirm that the loss of fertility as a function of maternal age has got nothing to do with the capacity of the oocyte to be fertilised, but everything to do with the competence of the fertilised egg to exhibit a normal pattern of embryonic development. As a consequence, assisted conception cannot assist women whose fertility has been lost as a result of advancing age. All IVF can ever achieve is to facilitate the juxtaposition and eggs and spermatozoa in preparation for fertilisation. It makes a perfectly rational form of treatment for male infertility where the lack of fertilising potential can be readily overcome by simply co-incubating male and female gametes together or physically injecting a spermatozoon into the ooplasm, as when ICSI is performed. However IVF makes no sense at all as a treatment for age-dependent female infertility. In keeping with this conclusion, live births following assisted conception therapy show exactly the same agedependent decline with maternal age as we see in the naturally conceived population (Alviggi et al. 2009).

Thus, while there is a tendency for women to postpone their childbearing years in the hope that assisted reproductive technology (ART) will be able to rescue their fertility in their late 30 s or early $40 \mathrm{~s}$, in practice, ART can do little if anything to assist women in this situation. The only possible technological fix that we can offer at the present time would be to have some oocytes preserved before the developmental potential of the female germ line declines. In this context, the use of vitrification techniques to preserve oocytes as a buffer against age-dependent infertility is certainly showing promise (Cobo et al. 2013). Importantly, the same technology may also be used to preserve oocytes before the administration of cytotoxic chemotherapeutic drugs in the treatment of cancer.

\section{Age and reproduction: the male perspective}

In contrast to women, there is no precipitous loss of fertility as men age. Male fertility may decline as a consequence of falling testosterone levels, but overall men are capable of conceiving children without taking recourse to ART, well into their 90s. However, as men age, the quality of their gametes deteriorates (Singh et al. 2003, Schmid et al. 2007, Das et al. 2013). As a result, the spermatozoa of ageing males contain much more DNA damage than their younger counterparts. Studies on the Brown Norway rat and the senescence accelerated mouse (SAM) both suggest that the origin of this agedependent increase in DNA damage in the germ line is oxidative, reflecting the general relationship between oxidative stress and ageing observed in most biological systems (Paul et al. 2011, Smith et al. 2013a). However, while there are several studies indicating that high levels of oxidative DNA damage are found in the spermatozoa of male infertility patients (De luliis et al. 2009a, 2009b, Aitken et al. 2010), there is, as yet, no direct evidence that the sperm DNA damage seen in older men is the result of oxidative stress. However, this is a reasonable supposition based on the animal data.

One thing we can be certain of is that as the age of the father increases, the risk of miscarriage and, if the pregnancy does carry to term, disease in the offspring, 
increases in parallel (Aitken \& Krausz 2001, Aitken et al. 2004, Kleinhaus et al. 2006). The range of pathologies associated with paternal age is significant and includes dominant genetic diseases such as Apert syndrome or achondroplasia (Crow 2000), complex neurological conditions such as bipolar disease, epilepsy, spontaneous schizophrenia and autism (Aitken \& Curry 2011, Goriely et al. 2013) as well as childhood carcinoma (Johnson et al. 2011). Furthermore, recent studies have demonstrated that a father's age at the moment of conception is linearly correlated with the mutational load carried by their offspring (Kong et al. 2012). The mechanisms that underpin this paternal-age-dependent rise in mutational load carried by children are certainly complex, involving a variety of factors such as replication error, jackpot mutations that lead to a loss of asymmetric division amongst the spermatogonial stem cell population and aberrant repair of sperm DNA damage in the oocyte, immediately after fertilisation (Shimura et al. 2002, Aitken et al. 2004, Crow 2012, Shinde et al. 2013).

Having a father older than 35 years may therefore pose a long-term risk to an individual's health; however, it may not all be bad news. Germ cells are remarkably adaptive and if, during the early stages of their development, they sense adverse circumstances prevailing in their immediate environment that can react by, for example, increasing telomerase activity and extending the length of telomeres in the differentiating spermatozoa. The cellular stress imposed by ageing represents one such factor. Thus, in response to the stresses associated with ageing, telomere length becomes extended in spermatozoa via mechanisms that may involve increases in telomerase activity and, possibly, the active selection of germ cell clones with long telomeres within the germinal epithelium (Aviv \& Susser 2013). The importance of this age-dependent increase in telomere length in spermatozoa is that this element of the genome is paternally inherited. We receive from our fathers half of our genome, including the sex chromosome that will determine our gender, a centriolar system that will subsequently orchestrate every cell division in our body and telomeres that will ultimately determine telomere length in our somatic cells. It is for this reason that telomere length in model cells such as leukocytes is highly correlated with the age of the father at birth and hence the length of the telomeres in his spermatozoa (Unryn et al. 2005, De Meyer et al. 2007, Njajou et al. 2007, Kimura et al. 2008, Prescott et al. 2012). Because longer leukocyte telomere length has been shown to be associated with reduced atherosclerotic risk in adults and increased survival in the elderly, there may be some advantages in having an older father.

The impact of paternal age on telomere length in the offspring is certainly highly significant $(\sim 15-20 \mathrm{bp}$ extension of telomere length in leukocytes for every year of paternal age). Furthermore the impact of paternal age on telomere length appears to be cumulative across successive generations (Eisenberg et al. 2012). The combination of an old father and an old grandfather could therefore have a dramatic positive effect on life expectancy as well as a negative risk of dominant genetic disease and neuropathologies of various kinds. Furthermore, because there is a universal trend towards older maternal and paternal ages at the moment of conception, we may see a progressive elongation of telomere length in future generations, which could have significant impacts on human health. The nature of this impact is, however, difficult to predict. There is still a great deal that we do not understand about telomere length, cell cycle number, longevity and the aetiology of conditions such as cancer. If susceptibility to the latter was just a question of replication number and the accompanying risk of an oncogenic mutation, cancer incidence across mammalian species would be a simple function of body mass and longevity and yet it is not; whales are no more sensitive to cancer than mice (Nagy et al. 2007). In future, it will be fascinating to see how the increase in mutational load and telomere length associated with advanced paternal age affect the net health trajectory of individuals with older parents.

\section{Other sources of stress in the germ line Smoking}

If the oxidative stress associated with advanced paternal age can have such a dramatic effect on the health and well-being of the progeny, we might ask what other conditions could create a similar kind of stress in the germ line. Smoking would clearly be one such example. Exposure to cigarette smoke is associated with oxidative stress in the male reproductive tract and the induction of high levels of oxidative DNA damage in the spermatozoa (Fraga et al. 1996). Such damage does not dramatically disrupt the fertility of the perpetrator; however, it does have a profound impact upon the health and well-being of their children, resulting in a significant increase in the incidence of childhood cancer (Lee et al. 2009).

The vulnerability of human spermatozoa to the effects of cigarette smoke is explained by the limited DNA repair capacity of these cells. When faced with an oxidised DNA base, these cells are competent to excise the adduct using a glycosylase OGG1 (8-oxoguanine glycosylase) in order to create an abasic site (Smith et al. 2013b). However the second enzyme in this pathway, apurinic/apyrimidinic endonuclease (APE1), is missing, so the remainder of the base excision repair pathway has to be completed in the oocyte following fertilisation (Fig. 1). The spermatozoon's reliance on OGG1 is significant because this enzyme is highly sensitive to inhibition by cadmium, one of the main contaminants of cigarette smoke (Benoff et al. 2000, Smith et al. 2013b). As a result, exposure of spermatozoa to cadmium leads to an accumulation of oxidised base adducts in the 


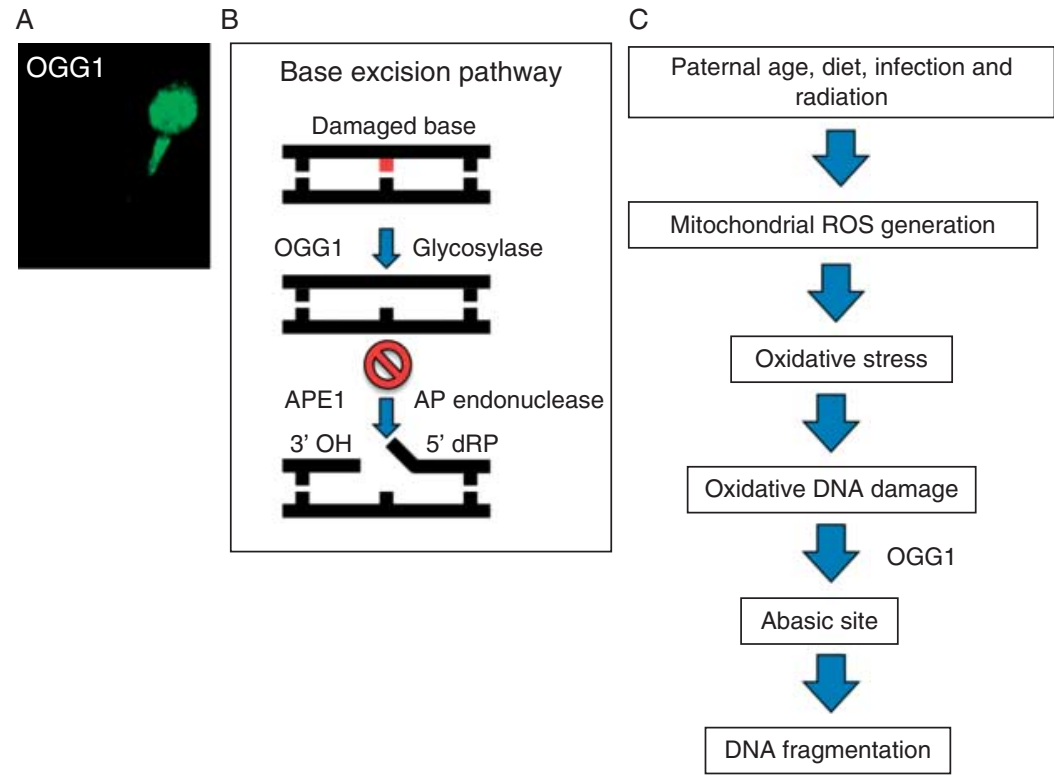

C

Figure 1 Aetiology of DNA strand breakage in human spermatozoa. (A) Spermatozoa possess an extremely truncated base excision repair pathway consisting of just the single enzyme, OGG1. Immunocytochemical studies indicate that this enzyme is associated with the chromatin in the sperm head as well as the DNA in the sperm mitochondria (Smith et al. 2013b). (B) The purpose of this enzyme is to cleave oxidised base adducts such as $8 \mathrm{OHdG}$ (coloured red) out of the DNA leaving an abasic site. The next enzyme in this pathway, APE1, is missing so the repair pathway stalls at this point. (C) We propose that a wide variety of extrinsic (radiation, diet, chemical exposure, etc.) and intrinsic (provision of antioxidant protection) factors can create a state of oxidative stress in the spermatozoa. Such stress triggers an apoptotic process characterised by high levels of ROS generation by the sperm mitochondria and the induction of high levels of $8 \mathrm{OHdG}$ formation. OGG1 removes these base adducts creating an abasic site that so destabilises the DNA backbone that fragmentation occurs. Endonuclease-mediated cleavage of DNA cannot occur in spermatozoa because the sperm nucleus is physically separated from the mitochondria and a majority of the cytoplasm (Koppers et al. 2011).

sperm nucleus as a result of inhibited OGG1 activity. The inefficient or aberrant repair of these lesions in the oocyte following fertilisation could account for the mutations associated with the increased risk of cancer in the children as a function of their father's smoking habit (Aitken et al. 2004).

\section{Obesity}

Smoking is just one of a number of factors capable of causing oxidative stress in the germ line; there are also many other factors. For example, obesity is known to be associated with the induction of systemic oxidative stress. This may arise as a result of the leakage of microbiome-derived lipopolysaccharide into the blood stream (a condition known as metabolic endotoxemia), which, in turn, triggers a systemic inflammatory reaction and associated oxidative stress (Neves et al. 2013). In addition, obese individuals are known to possess lowered antioxidant defences and a heightened generation of reactive oxygen species (ROS; Savini et al. 2013). The fact that obesity is capable of creating a systemic state of oxidative stress has been demonstrated by increased levels of lipid peroxidation products, including small molecular mass cytotoxic aldehydes such as malondiadehyde and 4-hydroxynonenal, as well as increased levels of oxidative damage to both DNA and protein (Vincent et al. 2007).

Whether the oxidative stress associated with obesity leads to a change in the conventional semen profile is the subject of some controversy (Palmer et al. 2012a, $2012 b$ ). Recent studies have suggested little relationship between the functional competence of spermatozoa, in terms of their ability to bind to the zona pellucida, and BMI (Sermondade et al. 2013a), although a recent metaanalysis has revealed odds ratios for oligozoospermia/ azoospermia of $1.28(1.06-1.55)$ for obese and 2.04 (1.59-2.62) for morbidly obese men (Sermondade et al. 2013b). A more consistent feature of obese males is the appearance of DNA fragmentation in the spermatozoa in association with oxidative stress (Palmer et al. 2012a, 2012b, Dupont et al. 2013). The DNA damage associated with obesity may be initiated at the spermatid stage of development while spermatids are differentiating into spermatozoa in a process known as spermiogenesis. Central to this process is an extensive remodelling of sperm chromatin to generate a highly compacted nucleus that is relatively resistant to DNA damage (Sawyer et al. 2001). Errors in this process can result in the differentiation of spermatozoa that are particularly vulnerable to oxidative attack following spermiation, as explained below. 


\section{Electromagnetic radiation}

In addition to smoking and obesity, exposure to various forms of electromagnetic radiation will trigger oxidative stress in the germ line. Thus, the simple application of heat will trigger free radical generation by sperm mitochondria and induce high levels of lipid peroxidation. This effect is only evident when spermatozoa are incubated at temperatures significantly above $37^{\circ} \mathrm{C}$; however, the clinical significance of such heat-induced stress is uncertain (De luliis et al. 2009a, 2009b). The presence of a varicocoele might constitute a possible exception, because this condition is associated with a sustained elevation of testicular temperature, particularly on the left hand side (Kulis et al. 2012), and the activation of ROS generation by the spermatozoa (Mostafa et al. 2001, Pasqualotto et al. 2008). Of greater clinical and biological interest may be reports of oxidative stress and DNA damage being caused in the germ line by radiofrequency electromagnetic radiation (RFEMR; De luliis et al. 2009a, 2009b). Importantly, the range of frequencies and specific absorption rates (SAR: the unit of measurement for the amount of RF energy absorbed by the body or cell suspension) employed in these studies cover those associated with mobile phones. The effects observed following exposure of human spermatozoa to RFEMR include an SAR-dependent increase in mitochondrial free radical generation, a loss of motility and an increase in DNA damage. Furthermore, highly significant correlations were observed between SAR, oxidative DNA damage and DNA fragmentation after exposure of human spermatozoa to RFEMR (De luliis et al. 2009a, 2009b). Similarly, exposure of the spermatocyte-derived cell line (GC2) to RFEMR has been shown to result in an increase in oxidative DNA damage in association with an increase in ROS generation (Liu et al. 2013). As the alkaline Comet assay failed to reveal any detectable DNA strand breakage in these cells, the authors conclude that RFEMR has insufficient energy to effect the direct induction of DNA strand breaks but may generate genotoxicity through the induction of oxidative DNA base damage in male germ cells (Liu et al. 2013). Similarly, in animal studies, exposure of rats to RFEMR has been shown to impair sperm motility and increase levels of oxidative stress in the testes and epididymis (Mailankot et al. 2009). The clinical relevance of such observations has been emphasised in several studies suggesting a relationship between extensive mobile phone use and DNA fragmentation in human spermatozoa (Agarwal et al. 2008, Rago et al. 2013). Data on the correlations between RFEMR-induced changes in sperm function and fertility are, however, inconsistent and somewhat controversial (Falzone et al. 2010, Merhi 2012, La Vignera et al. 2012). Additional well-controlled studies are clearly needed to establish whether such a relationship exists and, if it does, the nature of the underlying mechanism. Studies on the direct effects of RFEMR on human spermatozoa at least suggest a possible chain of cause-and-effect involving the induction of electron leakage from the sperm mitochondria, resulting in the formation of ROS and oxidative DNA damage that then triggers OGG1 to cleave out the damaged base, creating an abasic site that so destabilises the DNA backbone that DNA fragmentation occurs (Fig. 1).

\section{Chemical exposure}

The aetiology of DNA damage in spermatozoa may, in addition to lifestyle factors such as smoking, obesity and mobile phone usage, involve chemical exposures as a result of pollution, occupation or lifestyle. The number of chemicals that are potentially capable of causing oxidative DNA damage in the germ line is extensive and has recently been summarised (Aitken \& Roman 2008). Factors capable of causing oxidative stress in the germ line include pesticides, herbicides, alcohol, vinclozolin (an anti-androgenic fungicide), cobalt and the common environmental toxicant bisphenol A (Gazo et al. 2013, Reinardy et al. 2013, Wu et al. 2013). Careful dissection of the impact of such toxicants on the quality of spermatozoa is a high-priority task for the future that may go some way towards the development of preventative healthcare measures.

\section{Infertility treatment and oxidative DNA damage}

If ART is being used extensively to treat male infertility, and oxidative stress is a major cause of defective sperm function, then it stands to reason that many conceptions achieved in vitro will inevitably involve oxidatively damaged spermatozoa exhibiting high levels of unresolved 8-hydroxy, 2'-deoxyguanosine $(8 \mathrm{OHdG})$ formation. Under normal physiological circumstances, such spermatozoa would be prohibited from participating in fertilisation because of the collateral oxidative damage incurred by the sperm plasma membrane. However, with the advent of ICSI as a therapeutic technique. such spermatozoa can be readily coerced into fertilising the egg by physically injecting them into the ooplasm (Twigg et al. 1998). The consequences of such action are difficult to determine at the present time. By analogy with the data presented above on the consequences of fertilisation involving oxidatively damaged spermatozoa as a result of age or exposure to cigarette smoke, where a wide range of pathologies are observed in the offspring from autism to cancer, ICSI should be associated with an increase risk of disease in the progeny. The data on this point are not consistent. According to some authors, ICSI is associated with higher rates of congenital malformations (Davies et al. 2012, Tararbit et al. 2013, Yin et al. 2013). However, several studies have found that while 
ART as a whole may be associated with an increased risk of congenital malformations, there is no detectable difference between IVF and ICSI in this regard (Hansen et al. 2002, Zwink et al. 2012) The problem with such analyses is that the risk of creating a mutation in the embryo that will induce a recognisable phenotype at birth is extremely low. Rather than look for phenotypes in the F1, we would be better advised to conduct an analysis for overall mutational load by, for example, examining microsatellite DNA sequences. The recent application of such methods to reveal a linear correlation between paternal age and the mutational load subsequently carried by the offspring is testimony to the potential power of such analyses (Kong et al. 2012).

\section{Aetiology of DNA damage: the two-step hypothesis}

In terms of the aetiology of DNA damage in the male germ line, it may be relevant that in mice fed with a high fat diet, there is evidence of increased DNA damage as early as the spermatid stage of spermatogenesis, in association with a statistically significant increase in histone acetylation (Palmer et al. 2011). Alterations to histone acetylation during the critical chromatin-remodelling stages of spermiogenesis are correlated with poor protamination of DNA in the sperm nucleus. As poor protamination of sperm DNA is a consistent correlate of oxidative DNA damage in these cells (De luliis et al. 2009a, 2009b), these results suggest that the aetiology of DNA damage commonly involves a perturbation of chromatin remodelling during spermiogenesis as a result of which protamination is impeded (Fig. 2). This creates a state of vulnerability in the sperm chromatin towards oxidative stress and DNA damage. Fully protaminated sperm DNA approaches the physical limits of compaction and is practically crystalline in nature. The tightly compacted state of sperm chromatin offers these cells a certain level of protection against oxidative stress. In situations where such tight compaction is not achievable, the spermatozoa are vulnerable to DNA damage. For example, marsupial protamines possess no cysteines and, as a result, the inter- and intra-disulphide bridge formation that characterises the highly compacted sperm chromatin of eutherian species cannot be achieved. As a consequence, marsupial spermatozoa are particularly vulnerable to oxidative stress (Bennetts \& Aitken 2005). By contrast, within the Eutheria, the resistance of spermatozoa to oxidative attack increases with the number of cysteine residues present in the major sperm protamines (Enciso et al. 2011). Furthermore, the residual free thiols that are not involved in chromatin stabilisation can function as sacrificial antioxidants or chelators of metals involved in promoting free radical reactions (Kasprzak 2002). Oxidative stress may also directly impact upon the levels of compaction achievable in sperm chromatin because the lipid aldehydes generated as a consequence of this process are capable of covalently binding with any protamine thiols, thereby inhibiting the formation of disulphide bridges and disrupting the chromatin compaction process. Poorly protaminated chromatin is then vulnerable to oxidative attack. This sequence of events comprising an initial impairment of protamination during spermiogenesis to create a state of vulnerability followed by a direct free radical attack on the mature gamete constitutes the 'two-step hypothesis' of DNA damage and may help to frame future research in this area (Aitken et al. 2009).

\section{Epigenetic changes to the germ line}

The above discussion has been largely focused on how genetic and environmental factors can, by acting through the germ line, ultimately influence the genotype of the offspring. However, it should be emphasised that the germ line also makes important epigenetic contributions to
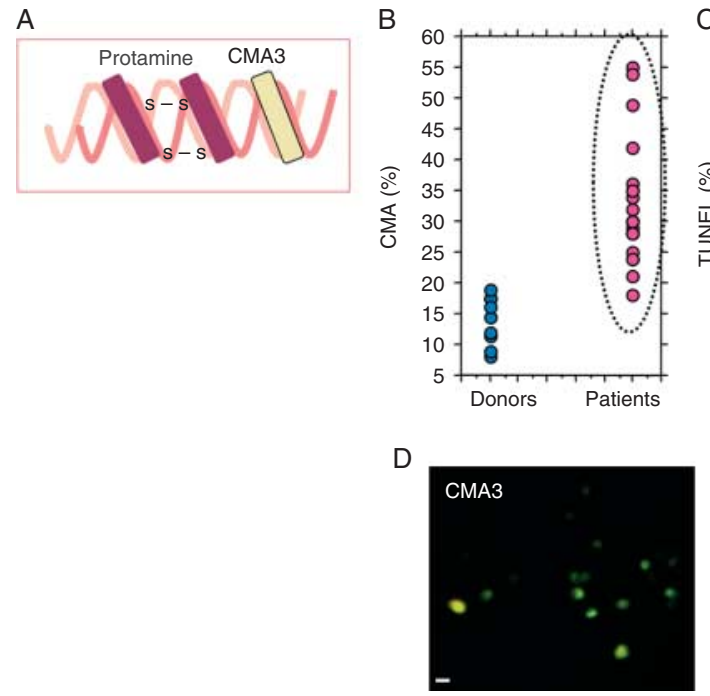
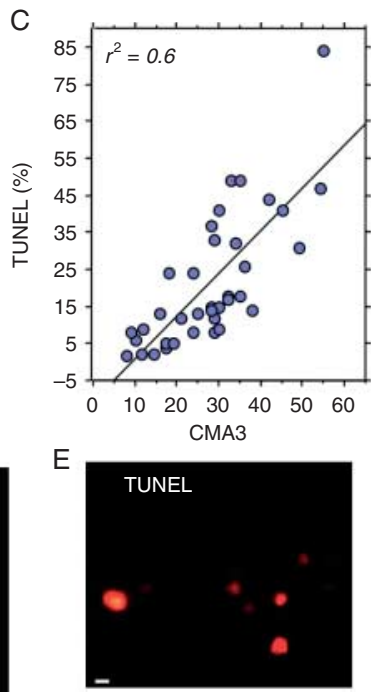

Figure 2 Chromatin compaction and the aetiology of DNA damage in the male germ line. (A) The level of sperm protamination can be measured by examining the incorporation of a fluorescent dye, chromomycin 3 (CMA3), into areas of the sperm nucleus, where protamination is deficient (Bianchi et al. 1996). (B) Assessment of chromatin protamination reveals a marked deficiency in the infertile male population. (C) A highly significant correlation is observed between the levels of DNA fragmentation detected in the sperm head with the aid of a TUNEL assay and a lack of chromatin protamination as suggested by CMA3 incorporation. (D and E) Micrographs illustrating the staining of human spermatozoa with the CMA3 and TUNEL assays respectively. 
normal embryonic development. For example, spermatozoa contribute myriad RNA species to the zygote, which have been proposed to modulate gene expression in the early embryo, as well as a carefully orchestrated pattern of nuclear histone retention and modification to direct embryonic differentiation. Furthermore, both the male and female germ lines express unique DNA methylation patterns that have a profound effect on fertility and the normality of development (Hammoud et al. 2009, 2011). Detailed discussion of these epigenetic modulators of embryonic development is beyond the scope of this review; however, the field has been extensively, and expertly, reviewed in this journal in the recent past (Teperek-Tkacz et al. 2011, Jenkins \& Carrell 2012).

\section{Conclusions}

In conclusion, improved reproductive healthcare is of paramount importance to the future well-being of our species. We desperately need novel forms of fertility regulation that will address the unmet need in this area and reduce our heavy reliance on induced abortion as a means of regulating fertility. There is an urgent need for reversible male contraceptives as well as dual-purpose formulations that provide simultaneous protection against both unwanted fertility and sexually transmitted disease. There is also a need for contraceptionon-demand that can be used by women at the extreme ends of their reproductive lifespan $(<19$ and $>40$ years of age) without having to resort to taking a-pill-a-day. Such a method would be activated around the time of coitus and would serve to block the earliest events in pregnancy from conception to implantation. Reinvigorating the role of pharmaceutical companies in contraceptive research and development will be critical to the success of such a venture.

On the other side of the reproductive coin, we need to address the high level of reliance on ART to address infertility in our species. The fact that infertility can be so readily treated using IVF and ICSI has discouraged research into the causes of human infertility and suppressed any attempts at preventative healthcare in this space. Age is clearly a major factor in the aetiology of female infertility and although technical developments such as oocyte vitrification may provide some measure of amelioration, the major need is for a new social contract around female reproduction that recognises the rightful aspirations of women to both raise a family and make a professional contribution to the workforce. In the case of male infertility, the major issues are around aetiology and the major role that the male germ line plays in defining the mutational load carried by the offspring. In this context our hypothesis is that such mutations may arise via the age-dependent expansion of mutant stem cell clones or the aberrant repair of oxidative sperm DNA damage in the oocyte. The latter is thought to be particularly important and will be driven by a range of environmental and lifestyle factors capable of inducing DNA damage in human spermatozoa. Identification of these factors, determining their routes of exposure and mechanisms-of-action on the germ line as well as the processes of DNA repair in the oocyte are all important tasks for the next generation of reproductive biologists to address.

\section{Declaration of interest}

The authors declare that there is no conflict of interest that could be perceived as prejudicing the impartiality of the review reported.

\section{Funding}

This review did not receive any specific grant from any funding agency in the public, commercial or not-for-profit sector.

\section{Acknowledgements}

The author gratefully acknowledges the support he has received from the Australian Research Council, the National Health and Medical Research Council, the Hunter Medical Research Institute and the University of Newcastle.

\section{References}

Agarwal A, Deepinder F, Sharma RK, Ranga G \& Li J 2008 Effect of cell phone usage on semen analysis in men attending infertility clinic: an observational study. Fertility and Sterility 89 124-128. (doi:10.1016/ j.fertnstert.2007.01.166)

Aitken RJ \& Curry BJ 2011 Redox regulation of human sperm function: from the physiological control of sperm capacitation to the etiology of infertility and DNA damage in the germ line. Antioxidants \& Redox Signaling 14 367-381. (doi:10.1089/ars.2010.3186)

Aitken RJ \& Krausz C 2001 Oxidative stress, DNA damage and the Y chromosome. Reproduction 122 497-506. (doi:10.1530/rep.0.1220497)

Aitken RJ \& Roman SD 2008 Antioxidant systems and oxidative stress in the testes. Oxidative Medicine and Cellular Longevity 1 15-24. (doi:10.4161/oxim.1.1.6843)

Aitken RJ, Koopman P \& Lewis SE 2004 Seeds of concern. Nature 432 48-52. (doi:10.1038/432048a)

Aitken RJ, Hughes LM, Griffith R \& Baker MA 2008 Bridging the gap between male and female fertility control; contraception-on-demand. Contraception 78 (Suppl 4) S28-S35. (doi:10.1016/j.contraception. 2008.03.020)

Aitken RJ, De Iuliis GN \& McLachlan RI 2009 Biological and clinical significance of DNA damage in the male germ line. International Journal of Andrology 32 46-56. (doi:10.1111/j.1365-2605.2008.00943.x)

Aitken RJ, De Iuliis GN, Finnie JM, Hedges A \& McLachlan RI 2010 Analysis of the relationships between oxidative stress, DNA damage and sperm vitality in a patient population: development of diagnostic criteria. Human Reproduction 25 2415-2426. (doi:10.1093/humrep/deq214)

Alberts SC, Altmann J, Brockman DK, Cords M, Fedigan LM, Pusey A, Stoinski TS, Strier KB, Morris WF \& Bronikowski AM 2013 Reproductive aging patterns in primates reveal that humans are distinct. PNAS 110 13440-13445. (doi:10.1073/pnas.1311857110)

Alviggi C, Humaidan P, Howles CM, Tredway D \& Hillier SG 2009 Biological versus chronological ovarian age: implications for assisted reproductive technology. Reproductive Biology and Endocrinology 7 101. (doi:10.1186/1477-7827-7-101)

Australian Bureau of Statistics 2012 Births Australia, 2011, Cat no 3301.0, Canberra. 
Aviv A \& Susser E 2013 Leukocyte telomere length and the father's age enigma: implications for population health and for life course. International Journal of Epidemiology 42 457-462. (doi:10.1093/ije/ dys236)

Baird DT 2001 Antigestogens: the holy grail of contraception. Reproduction, Fertility, and Development 13 723-728. (doi:10.1071/RD01061)

Baird DT \& Glasier AF 1999 Science, medicine, and the future. BMJ 319 969-972. (doi:10.1136/bmj.319.7215.969)

Barot S 2008 Back to basics: the rationale for increased funds for international family planning. Guttmacher Policy Review 11 13-18.

Bennetts LE \& Aitken RJ 2005 A comparative study of oxidative DNA damage in mammalian spermatozoa. Molecular Reproduction and Development 71 77-87. (doi:10.1002/mrd.20285)

Benoff S, Jacob A \& Hurley IR 2000 Male infertility and environmental exposure to lead and cadmium. Human Reproduction Update 6 107-121. (doi:10.1093/humupd/6.2.107)

Bianchi PG, Manicardi G, Bizzaro D, Campana A, Bianchi U \& Sakkas D 1996 Use of the guanine-cytosine (GC) specific fluorochrome, chromomycin A3, as an indicator of poor sperm morphology. Journal of Assisted Reproduction and Genetics 13 246-250. (doi:10. 1007/BF02065944)

Cetinkaya MB, Siano LJ, Benadiva C, Sakkas D \& Patrizio P 2013 Reproductive outcome of women 43 years and beyond undergoing ART treatment with their own oocytes in two Connecticut university programs. Journal of Assisted Reproduction and Genetics 30 673-678. (doi:10.1007/s10815-013-9981-5)

Chambers GM, Illingworth PJ \& Sullivan EA 2011 Assisted reproductive technology: public funding and the voluntary shift to single embryo transfer in Australia. Medical Journal of Australia 195 594-598. (doi:10.5694/mja10.11448)

Check JH, Burgos S, Slovis B \& Wilson C 2013 Embryo apoptosis may be a significant contributing factor in addition to aneuploidy inhibiting live deliveries once a woman reaches age 45. Clinical and Experimental Obstetrics \& Gynecology 40 22-23.

Cobo A, Garcia-Velasco JA, Domingo J, Remohí J \& Pellicer A 2013 Is vitrification of oocytes useful for fertility preservation for age-related fertility decline and in cancer patients? Fertility and Sterility 99 1485-1495. (doi:10.1016/j.fertnstert.2013.02.050)

Crow JF 2000 The origins, patterns and implications of human spontaneous mutation. Nature Reviews. Genetics 1 40-47. (doi:10.1038/35049558)

Crow JF 2012 Upsetting the dogma: germline selection in human males. PLoS Genetics 8 e1002535. (doi:10.1371/journal.pgen.1002535)

Darroch JE 2013 Trends in contraceptive use. Contraception 87 259-263. (doi:10.1016/j.contraception.2012.08.029)

Das M, Al-Hathal N, San-Gabriel M, Phillips S, Kadoch IJ, Bissonnette F, Holzer H \& Zini A 2013 High prevalence of isolated sperm DNA damage in infertile men with advanced paternal age. Journal of Assisted Reproduction and Genetics 30 843-848. (doi:10.1007/s10815-0130015-0)

Davies MJ, Moore VM, Willson KJ, Van Essen P, Priest K, Scott H, Haan EA \& Chan A 2012 Reproductive technologies and the risk of birth defects. New England Journal of Medicine 366 1803-1813. (doi:10.1056/ NEJMoa1008095)

De Iuliis GN, Newey RJ, King BV \& Aitken RJ 2009a Mobile phone radiation induces reactive oxygen species production and DNA damage in human spermatozoa in vitro. PLOS ONE 4 e6446. (doi:10.1371/ journal.pone.0006446)

De Iuliis GN, Thomson LK, Mitchell LA, Finnie JM, Koppers AJ, Hedges A, Nixon B \& Aitken RJ $2009 b$ DNA damage in human spermatozoa is highly correlated with the efficiency of chromatin remodeling and the formation of 8-hydroxy-2'-deoxyguanosine, a marker of oxidative stress. Biology of Reproduction 81 517-524. (doi:10.1095/biolreprod.109. 076836)

De Meyer T, Rietzschel ER, De Buyzere ML, De Bacquer D, Van Criekinge W, De Backer GG, Gillebert TC, Van Oostveldt P, Bekaert S \& Asklepios investigators 2007 Paternal age at birth is an important determinant of offspring telomere length. Human Molecular Genetics 16 3097-3102. (doi:10.1093/hmg/ddm271)

Dupont C, Faure C, Sermondade N, Boubaya $M$, Eustache F, Clément P, Briot P, Berthaut I, Levy V, Cedrin-Durnerin I et al. 2013 Obesity leads to higher risk of sperm DNA damage in infertile patients. Asian Journal of Andrology.
Enciso M, Johnston SD \& Gosálvez J 2011 Differential resistance of mammalian sperm chromatin to oxidative stress as assessed by a twotailed comet assay. Reproduction, Fertility, and Development 23 633-637. (doi:10.1071/RD10269)

Eisenberg DT, Hayes MG \& Kuzawa CW 2012 Delayed paternal age of reproduction in humans is associated with longer telomeres across two generations of descendants. PNAS 109 10251-10256. (doi:10.1073/ pnas.1202092109)

Falzone N, Huyser C, Franken DR \& Leszczynski D 2010 Mobile phone radiation does not induce pro-apoptosis effects in human spermatozoa. Radiation Research 174 169-176. (doi:10.1667/RR2091.1)

Fraga CG, Motchnik PA, Wyrobek AJ, Rempel DM \& Ames BN 1996 Smoking and low antioxidant levels increase oxidative damage to sperm DNA. Mutation Research 351 199-203. (doi:10.1016/0027-5107 (95)00251-0)

Fragouli E, Alfarawati S, Spath K, Jaroudi S, Sarasa J, Enciso M \& Wells D 2013 The origin and impact of embryonic aneuploidy. Human Genetics 132 1001-1013. (doi:10.1007/s00439-013-1309-0)

Gazo I, Linhartova P, Shaliutina A \& Hulak M 2013 Influence of environmentally relevant concentrations of vinclozolin on quality, DNA integrity, and antioxidant responses of sterlet Acipenser ruthenus spermatozoa. Chemico-Biological Interactions 203 377-385. (doi:10. 1016/j.cbi.2013.01.004)

Glasier A, Thong KJ, Dewar M, Mackie M \& Baird DT 1992 Mifepristone (RU486) compared with high-dose estrogen and progestogen for emergency postcoital contraception. New England Journal of Medicine 327 1041-1044. (doi:10.1056/NEJM199210083271501)

Goriely A, McGrath JJ, Hultman CM, Wilkie AO \& Malaspina D 2013 "Selfish spermatogonial selection": a novel mechanism for the association between advanced paternal age and neurodevelopmental disorders. American Journal of Psychiatry 170 599-608. (doi:10.1176/ appi.ajp.2013.12101352)

Hammoud SS, Nix DA, Zhang H, Purwar J, Carrell DT \& Cairns BR 2009 Distinctive chromatin in human sperm packages genes for embryo development. Nature 460 473-478. (doi:10.1038/nature08162)

Hammoud SS, Nix DA, Hammoud AO, Gibson M, Cairns BR \& Carrell DT 2011 Genome-wide analysis identifies changes in histone retention and epigenetic modifications at developmental and imprinted gene loci in the sperm of infertile men. Human Reproduction 26 2558-2569. (doi:10. 1093/humrep/der192)

Hansen M, Kurinczuk JJ, Bower C \& Webb S 2002 The risk of major birth defects after intracytoplasmic sperm injection and in vitro fertilization. New England Journal of Medicine 346 725-730. (doi:10.1056/ NEJMoa010035)

Heffner LJ 2004 Advanced maternal age - how old is too old? New England Journal of Medicine 351 1927-1929. (doi:10.1056/NEJMp048087)

Human Fertilisation and Embryology Authority 2010 Facts and figures 2008: fertility problems and treatment.

Hvidtjørn D, Grove J, Schendel D, Schieve LA, Sværke C, Ernst E \& Thorsen P 2011 Risk of autism spectrum disorders in children born after assisted conception: a population-based follow-up study. Journal of Epidemiology and Community Health 65 497-502. (doi:10.1136/jech. 2009.093823)

Jenkins TG \& Carrell DT 2012 The sperm epigenome and potential implications for the developing embryo. Reproduction 143 727-734. (doi:10.1530/REP-11-0450)

Johnson KJ, Carozza SE, Chow EJ, Fox EE, Horel S, McLaughlin CC, Mueller BA, Puumala SE, Reynolds P, Von Behren J et al. 2011 Birth characteristics and childhood carcinomas. British Journal of Cancer 105 1396-1401. (doi:10.1038/bjc.2011.359)

Kasprzak KS 2002 Oxidative DNA and protein damage in metal-induced toxicity and carcinogenesis. Free Radical Biology \& Medicine 32 958-967. (doi:10.1016/S0891-5849(02)00809-2)

Kimura M, Cherkas LF, Kato BS, Demissie S, Hjelmborg JB, Brimacombe M, Cupples A, Hunkin JL, Gardner JP, Lu X et al. 2008 Offspring's leukocyte telomere length, paternal age, and telomere elongation in sperm. PLoS Genetics 4 e37. (doi:10.1371/journal.pgen.0040037)

Kleinhaus K, Perrin M, Friedlander Y, Paltiel O, Malaspina D \& Harlap S 2006 Paternal age and spontaneous abortion. Obstetrics and Gynecology 108 369-377. (doi:10.1097/01.AOG.0000224606.26514.3a) 
Kong A, Frigge ML, Masson G, Besenbacher S, Sulem P, Magnusson G, Gudjonsson SA, Sigurdsson A, Jonasdottir A, Jonasdottir A et al. 2012 Rate of de novo mutations and the importance of father's age to disease risk. Nature 488 471-475. (doi:10.1038/nature11396)

Konner M \& Worthman C 1980 Nursing frequency, gonadal function, and birth spacing among !Kung hunter-gatherers. Science 207 788-791. (doi:10.1126/science.7352291)

Koppers AJ, Mitchell LA, Wang P, Lin M \& Aitken RJ 2011 Phosphoinositide 3-kinase signalling pathway involvement in a truncated apoptotic cascade associated with motility loss and oxidative DNA damage in human spermatozoa. Biochemical Journal 436 687-698. (doi:10.1042/ BJ20110114)

Kulis T, Kolaric D, Karlovic K, Knezevic M, Antonini S \& Kastelan Z 2012 Scrotal infrared digital thermography in assessment of varicocele - pilot study to assess diagnostic criteria. Andrologia 44 (Suppl 1) 780-785. (doi:10.1111/j.1439-0272.2011.01265.x)

La Vignera S, Condorelli RA, Vicari E, D'Agata R \& Calogero A 2012 Effects of the exposure to mobile phones on male reproduction: a review of the literature. Journal of Andrology 33 350-356. (doi:10.2164/jandrol.111.014373)

Lee KM, Ward MH, Han S, Ahn HS, Kang HJ, Choi HS, Shin HY, Koo HH, Seo JJ, Choi JE et al. 2009 Paternal smoking, genetic polymorphisms in CYP1A1 and childhood leukemia risk. Leukemia Research 33 250-258. (doi:10.1016/j.leukres.2008.06.031)

Liu C, Duan W, Xu S, Chen C, He M, Zhang L, Yu Z \& Zhou Z 2013 Exposure to $1800 \mathrm{MHz}$ radiofrequency electromagnetic radiation induces oxidative DNA base damage in a mouse spermatocyte-derived cell line. Toxicology Letters 218 2-9. (doi:10.1016/j.toxlet.2013.01.003)

Mailankot M, Kunnath AP, Jayalekshmi H, Koduru B \& Valsalan R 2009 Radio frequency electromagnetic radiation (RF-EMR) from GSM $(0.9 / 1.8 \mathrm{GHz})$ mobile phones induces oxidative stress and reduces sperm motility in rats. Clinics 64 561-565. (doi:10.1590/S180759322009000600011)

Merhi ZO 2012 Challenging cell phone impact on reproduction: a review. Journal of Assisted Reproduction and Genetics 29 293-297. (doi:10. 1007/s10815-012-9722-1)

Mostafa T, Anis TH, El-Nashar A, Imam H \& Othman IA 2001 Varicocelectomy reduces reactive oxygen species levels and increases antioxidant activity of seminal plasma from infertile men with varicocele. International Journal of Andrology 24 261-265. (doi:10.1046/j.13652605.2001.00296.x)

Nagy JD, Victor EM \& Cropper JH 2007 Why don't all whales have cancer? A novel hypothesis resolving Peto's paradox Integrative and Comparative Biology 47 317-328. (doi:10.1093/icb/icm062)

Neves AL, Coelho J, Couto L, Leite-Moreira A \& Roncon-Albuquerque R 2013 Metabolic endotoxemia: a molecular link between obesity and cardiovascular risk. Journal of Molecular Endocrinology 51 R51-64. (doi:10.1530/JME-13-0079)

Njajou OT, Cawthon RM, Damcott CM, Wu SH, Ott S, Garant MJ, Blackburn EH, Mitchell BD, Shuldiner AR \& Hsueh WC 2007 Telomere length is paternally inherited and is associated with parental lifespan. PNAS 104 12135-12139. (doi:10.1073/pnas.0702703104)

Palmer NO, Fullston T, Mitchell M, Setchell BP \& Lane M 2011 SIRT6 in mouse spermatogenesis is modulated by diet-induced obesity. Reproduction, Fertility, and Development 23 929-939. (doi:10.1071/ RD10326)

Palmer NO, Bakos HW, Fullston T \& Lane M 2012a Impact of obesity on male fertility, sperm function and molecular composition. Spermatogenesis 2 253-263. (doi:10.4161/spmg.21362)

Palmer NO, Bakos HW, Owens JA, Setchell BP \& Lane M 2012b Diet and exercise in an obese mouse fed a high-fat diet improve metabolic health and reverse perturbed sperm function. American Journal of Physiology. Endocrinology and Metabolism 302 E768-E780. (doi:10.1152/ajpendo. 00401.2011)

Pasqualotto FF, Sundaram A, Sharma RK, Borges E Jr, Pasqualotto EB \& Agarwal A 2008 Semen quality and oxidative stress scores in fertile and infertile patients with varicocele. Fertility and Sterility 89 602-607. (doi:10.1016/j.fertnstert.2007.03.057)

Paul C, Nagano M \& Robaire B 2011 Aging results in differential regulation of DNA repair pathways in pachytene spermatocytes in the Brown Norway rat. Biology of Reproduction 85 1269-1278. (doi:10.1095/ biolreprod.111.094219)
Prescott J, Du M, Wong JY, Han J \& De Vivo I 2012 Paternal age at birth is associated with offspring leukocyte telomere length in the nurses' health study. Human Reproduction 27 3622-3631. (doi:10.1093/humrep/ des314)

Rago R, Salacone P, Caponecchia L, Sebastianelli L, Marcucci I, Calogero AE, Condorelli R, Vicari E, Morgia G, Favilla V et al. 2013 The semen quality of the mobile phone users. Journal of Endocrinological Investigation. In press.

Reinardy HC, Syrett JR, Jeffree RA, Henry TB \& Jha AN 2013 Cobaltinduced genotoxicity in male zebrafish (Danio rerio), with implications for reproduction and expression of DNA repair genes. Aquatic Toxicology 126 224-230. (doi:10.1016/j.aquatox.2012.11.007)

Savini I, Catani MV, Evangelista D, Gasperi V \& Avigliano L 2013 Obesityassociated oxidative stress: strategies finalized to improve redox state. International Journal of Molecular Sciences 14 10497-10538. (doi:10. 3390/ijms140510497)

Sawyer DE, Roman SD \& Aitken RJ 2001 Relative susceptibilities of mitochondrial and nuclear DNA to damage induced by hydrogen peroxide in two mouse germ cell lines. Redox Report 6 182-184. (doi:10.1179/135100001101536157)

Schmid TE, Eskenazi B, Baumgartner A, Marchetti F, Young S, Weldon R, Anderson D \& Wyrobek AJ 2007 The effects of male age on sperm DNA damage in healthy non-smokers. Human Reproduction 22 180-187. (doi:10.1093/humrep/del338)

Sedgh G, Singh S, Shah IH, Åhman E, Henshaw SK \& Bankole A 2012 Induced abortion: incidence and trends worldwide from 1995 to 2008. Lancet 379 625-632. (doi:10.1016/S0140-6736(11)61786-8)

Sermondade N, Dupont C, Faure C, Boubaya M, Cédrin-Durnerin I, Chavatte-Palmer P, Sifer C \& Lévy R 2013a Body mass index is not associated with sperm-zona pellucida binding ability in subfertile males. Asian Journal of Andrology 15 622-625. (doi:10.1038/aja.2013.65)

Sermondade N, Faure C, Fezeu L, Shayeb AG, Bonde JP, Jensen TK, Van Wely M, Cao J, Martini AC, Eskandar M et al. 2013b BMl in relation to sperm count: an updated systematic review and collaborative metaanalysis. Human Reproduction Update 19 221-231. (doi:10.1093/ humupd/dms050)

Shimura T, Inoue M, Taga M, Shiraishi K, Uematsu N, Takei N, Yuan ZM, Shinohara T \& Niwa O 2002 p53-dependent S-phase damage checkpoint and pronuclear cross talk in mouse zygotes with X-irradiated sperm. Molecular and Cellular Biology 22 2220-2228. (doi:10.1128/MCB.22.7.2220-2228.2002)

Shinde DN, Elmer DP, Calabrese P, Boulanger J, Arnheim N \& Tiemann-Boege I 2013 New evidence for positive selection helps explain the paternal age effect observed in achondroplasia. Human Molecular Genetics 22 4117-4126. (doi:10.1093/hmg/ddt260)

Shufaro Y \& Schenker JG 2012 Pregnancies beyond the human biological fecundity. Women's Health 8 49-55. (doi:10.2217/whe.11.83)

Singh NP, Muller CH \& Berger RE 2003 Effects of age on DNA doublestrand breaks and apoptosis in human sperm. Fertility and Sterility $\mathbf{8 0}$ 1420-1430. (doi:10.1016/j.fertnstert.2003.04.002)

Smith TB, De luliis GN, Lord T \& Aitken RJ 2013a The senescenceaccelerated mouse prone 8 as a model for oxidative stress and impaired DNA repair in the male germ line. Reproduction 146 253-262. (doi:10.1530/REP-13-0186)

Smith TB, Dun MD, Smith ND, Curry BJ, Connaughton HS \& Aitken RJ $2013 b$ The presence of a truncated base excision repair pathway in human spermatozoa that is mediated by OGG1. Journal of Cell Science 126 1488-1497. (doi:10.1242/jcs.121657)

Sunderam S, Kissin DM, Flowers L, Anderson JE, Folger SG, Jamieson DJ, Barfield WD \& Centers for Disease Control and Prevention (CDC) 2012 Assisted reproductive technology surveillance - United States, 2009. Morbidity and Mortality Weekly Report. Surveillance Summaries 61 $1-23$.

Tararbit K, Lelong N, Thieulin AC, Houyel L, Bonnet D, Goffinet F, Khoshnood B \& EPICARD Study Group 2013 The risk for four specific congenital heart defects associated with assisted reproductive techniques: a population-based evaluation. Human Reproduction 28 367-374. (doi:10.1093/humrep/des400)

Teperek-Tkacz M, Pasque V, Gentsch G \& Ferguson-Smith AC 2011 Epigenetic reprogramming: is deamination key to active DNA demethylation? Reproduction 142 621-632. (doi:10.1530/REP-11-0148) 
Twenge J 2013 Is it really too late for a baby. Observer Magazine 24-29 (July 14 2013).

Twigg JP, Irvine DS \& Aitken RJ 1998 Oxidative damage to DNA in human spermatozoa does not preclude pronucleus formation at intracytoplasmic sperm injection. Human Reproduction 13 1864-1871. (doi:10.1093/humrep/13.7.1864)

Unryn BM, Cook LS \& Riabowol KT 2005 Paternal age is positively linked to telomere length of children. Aging Cell 4 97-101. (doi:10.1111/j.14749728.2005.00144.x)

Vincent HK, Innes KE \& Vincent KR 2007 Oxidative stress and potential interventions to reduce oxidative stress in overweight and obesity. Diabetes, Obesity \& Metabolism 9 813-839. (doi:10.1111/j.1463-1326. 2007.00692.x)

Wu HJ, Liu C, Duan WX, Xu SC, He MD, Chen CH, Wang Y, Zhou Z, Yu ZP, Zhang L et al. 2013 Melatonin ameliorates bisphenol A-induced DNA damage in the germ cells of adult male rats. Mutation Research $\mathbf{7 5 2}$ 57-67. (doi:10.1016/j.mrgentox.2013.01.005)
Yin L, Hang F, Gu LJ, Xu B, Ma D \& Zhu GJ 2013 Analysis of birth defects among children 3 years after conception through assisted reproductive technology in China. Birth Defects Research. Part A, Clinical and Molecular Teratology 97 744-749. (doi:10.1002/bdra.23116)

Zwink N, Jenetzky E, Schmiedeke E, Schmidt D, Märzheuser S, GrasshoffDerr S, Holland-Cunz S, Weih S, Hosie S, Reifferscheid P et al. 2012 Assisted reproductive techniques and the risk of anorectal malformations: a German case-control study. Orphanet Journal of Rare Diseases 7 65. (doi:10.1186/1750-1172-7-65)

Received 21 August 2013

First decision 7 October 2013

Revised manuscript received 9 October 2013

Accepted 4 November 2013 